Nuntius Antiquus, Belo Horizonte, v. 13, n. 2, p. 137-152, 2017

\title{
Teseu entre as disforias da glória e as euforias do eu - as marcas da mudança na poesia romana
}

\section{Theseus Between the Dysphoria of Glory and the Euphoria of Self - the Signals of Change in Roman Poetry}

\author{
Wellington Ferreira Lima \\ Departamento de Letras \\ Universidade Federal de Alfenas, Alfenas, Minas Gerais / Brasil \\ wellington.lima@unifal-mg.edu.br
}

Resumo: Este trabalho é o produto do esforço de revisitar parte de um estudo de 10 anos atrás, que tinha escopo essencialmente estruturalista, e de submetê-lo a um debate transdisciplinar. O objetivo inicial é o de avaliar a construção da personagem Teseu no Carmen LXIV de Catulo. Uma leitura estruturalista dos discursos presente no texto apontou para uma contraposição entre as construções de Teseu e Ariadne no sistema, na forma da oposição pensamento neotérico, + lírico-passional, + eufórico versus pensamento utilitarista da arte, + heróico, + disfórico. A expansão dos resultados iniciais ao debate transdisciplinar leva à conclusão de um indicador da tendência autonomizante da poesia latina do séc. I a.C., o qual se soma a outros indicadores, reforçando a ideia de um pensamento da aísthesis da obra de arte na Roma Clássica.

Palavras-chave: Catulo; poetae novi; poética clássica.

Abstract: The present study is the result of the effort to revisit the part of a 10 year-work which had scope mainly structurally, and to submit it to a trans-disciplinary debate. The study's initial objective is to evaluate the building of the character Theseus in Carmen LXIV of Catullus. A structuralist reading of the discourses present in the text pointed to a contraposition between the building of Theseus and Ariadne in the system in the form of the neoteric thought, + lyrical-passionate, + euphoric versus an utilitarian view of art, +heroic, +dysphoric. The initial result expansion to the trans-disciplinary debate leads to the conclusion of an autonomizing tendency indicator of Latin poetry of the 1st century B.C., to which is added other indicators reinforcing the idea of an aisthesis thought of the artwork in Classical Rome.

Keywords: Catullus; poetae novi; classical poetics. 
Este artigo é o produto resultante do gentil convite da Profa. Maria Cecília de Miranda Nogueira Coelho, em nome da comissão organizadora do "VII Simpósio Internacional Lendo, Vendo e Ouvindo o Passado", a repensar parte de um trabalho realizado em 2006 sob a orientação da Profa. Sandra Bianchet, não apenas na distância temporal, mas, sobretudo, pelo saudável debate transdisciplinar que o evento proporcionara. Além dessa breve contextualização, estas linhas se dedicam a agradecer a essas duas provocadoras do trabalho, além dos demais participantes do evento, em especial aos professores Celso de Oliveira Vieira (UFMG/ UFPA) e Frederick Ahl (Cornell University), cujos questionamentos e contribuições foram muito bem recebidos.

O projeto do trabalho original (LIMA, 2007) consistiu em propor uma significação para a releitura do mito, especificamente o de Teseu, na obra de Catulo. Nessa revisão, uma parte importante desta mesma pesquisa - a construção dos personagens enunciados e dos sujeitos da enunciação - tornou-se ponto inicial para expandir um pouco a reflexão para a maneira como o texto permite um vislumbre de parte da configuração do pensamento estético romano, ou, simplesmente, da configuração do pensamento romano.

Em princípio, faremos uma breve apresentação do problema da construção das personagens centrais de uma das digressões do labiríntico poema de Catulo que tomaremos como nosso fio condutor. "El 64 es, en muchos aspectos, un poema desconcertante, un laberinto difícil de penetrar sin plano de algún tipo." (KENNEY; CLAUSEN, 1989, p. 217).

Tal poema é uma sucessão de digressões com base em uma narrativa, hipoteticamente central, constituída pelas bodas de Peleu e Tétis. Como é de se perceber, é possível fragmentá-lo em três grandes partes, as quais poderiam, também, ser subdivididas. O tema central das Bodas de Peleu e Tétis é cercado de outras narrativas: a primeira é a viagem dos argonautas e o momento da paixão de Peleu; após a apresentação do tema central, aparece $o$ assentimento das bodas por Júpiter; retoma-se a narrativa das bodas, seu início, a comemoração mortal, o manto nupcial. Este é o ponto de origem da mais longa digressão - sobre a qual não seria exagero afirmar que abriga outras narrativas encaixadas - Ariadne 
em Dia. O bordado inicia-se pelo despertar de Ariadne na ilha, e logo se desvia para a luta de Teseu e Minotauro, prosseguindo-se o longo lamento de Ariadne. O manto ainda abre espaço para descrever a morte de Egeu e finda com o breve prenúncio da chegada de Baco em busca da amada Ariadne. O fim da descrição do manto abre espaço para a terceira parte da narrativa das bodas: a chegada dos imortais. Aqui, predomina o canto das Parcas que chegam à festa e que se dedica a predizer o futuro do filho do casal, Aquiles. Por fim, o poema encerra-se com um epílogo que contrapõe o tempo dos heróis e o tempo do poeta.

Já de início, o fragmento que apresenta o manto, i.e., a narrativa de Ariadne e Teseu, anuncia que falará das virtudes dos heróis.

haec uestis priscis hominum uariata figuris heroum mira uirtutes indicat arte.

O manto, vário de figuras priscas de homens, com fina arte heróis desenha e sua coragem.

(CATULO, 1996, v.: 50-51.)

No entanto, é de se notar que Ariadne destaca-se como a figura com mais vigor no texto. Sem dúvida, ela é a personagem mais marcante desse texto, mas pode-se notar, também, em uma análise quantitativa, que mais de dois terços dos versos são dedicados a Teseu (151 versos dos 214 versos que tratam do manto), sendo coerente com os dois versos que marcam o início do fragmento. Temos aqui um primeiro complicador: a versão ainda fala de Teseu ou ele é secundário na narrativa?

As informações de que carece a análise não se apresentam, como na maior parte das fontes que tratam do mito de Teseu, de maneira organizada ou explícita; a natureza da composição catuliana torna intrincada a investigação e deixa os elementos da narrativa mítica dispersos nos discursos das personagens ou da persona poética do epílio. Assim, defrontamo-nos de imediato com mais um complicador: a existência de três discursos encaixados na digressão do poema que constitui o evento de Teseu e Ariadne, quais sejam: o de um narrador da aventura, o de Ariadne e o de Egeu. 
A primeira referência que nos dá Catulo aponta para o ramo mais corrente das versões, no qual Ariadne é deixada pelo herói ateniense na ilha de Naxos. Quanto às razões que teriam levado Teseu a abandonar a princesa, nada é muito claro; dir-se-ia, até, que há uma ambiguidade. Explicitamente, não há, pela voz do narrador, uma razão para o abandono, seja temor ou vontade. Encontramos, reincidindo por três vezes, além de uma vez proferido por Ariadne, o adjetivo immemor ("esquecido", "sem memória"). Na primeira delas, mais especificamente no verso 58, parece ser apenas um qualificativo de Teseu, sem qualquer complemento, como poderia vir a sugerir o irrita promissa ("promessa sem valor") do verso seguinte.

immemor at iuuenis fugiens pellit uada remis, irrita uentosae linquens promissa procellae.

Mas o jovem não lembra e foge e fere a onda a remo e deixa a vã promessa à chuva, aos ventos.

(CATULO, 1996, v.:58-59).

Os próximos usos são semelhantes, muito embora o do verso 123 pareça sugerir um objeto para o esquecimento, a própria Ariadne; nesse sentido, é necessário ressaltar que o sintagma a que pertence o termo é centralizado por liquerit ("perder", “deixar esvair"), sugerindo não que ele deixa Ariadne, mas que a perde ou a deixa-se perder (como pode vir a sugerir a tradução de Oliva Neto), sobretudo se considerarmos que discendens pode ser traduzido por "afastando-se", e não necessariamente por "fugindo".

aut ut uecta rati spumosa ad litora Diae venerit, aut ut eam deuinctam lumina somno liquerit immemori discedens pectore coniunx?

[Relembro] como a nau levou-a às praias espumosas de Dia, ou como, de olhos pregados de sono, lá o amante a deixou, fugindo sem lembrar?

(CATULO, 1996, v.:121-12). 
De qualquer forma, o esquecimento não se refere às juras que fizera Teseu, mas, o que mais surpreende, à própria jovem. Ora, tal interpretação seria insustentável se observarmos que seria inverossímil que o herói pudesse esquecer-se daquela que lhe propiciara meios para a vitória - o narrador da história no poema fala do fio que Ariadne dera a Teseu -, principalmente em um momento de calmaria, quando se viam, já, fora das terras de Minos. Caberia, então, fazer recair sobre a perfídia de Teseu todas as razões que levaram ao abandono de Ariadne?

Não se pode responder à questão acima levantada sem se ter em conta o fim dessa narrativa no poema. Como na maior parte das versões, em Catulo, há a participação de Dioniso no episódio de Naxos. A descrição, quase pictórica, feita pelo poeta, nos fornece uma imagem na qual, em um ponto central, Ariadne observa o navio que parte, enquanto, ao fundo, surge Iaco no horizonte, já incesum amore, buscando Ariadne.

Ora, se não há uma indicação explícita que permita a afirmação segura de que Dioniso foi o manipulador do herói no evento, as pistas para a leitura, contudo, não são desconsideráveis. Em primeiro lugar, pelo que é dito acima: o deus não se encontra com Ariadne em Dia e apaixona-se; pelo contrário, ele aparece indo a seu encontro, já tomado por furor amante. Isso corroboraria para que julgássemos tratar-se da mesma tradição do mito atestada por Higino, ou por algumas versões iconográficas, fazendo-nos inferir uma intervenção do deus pré-partida de Teseu. Talvez a insistência do narrador em immemor diga respeito não ao que Teseu teria esquecido mas ao próprio esquecimento de que o herói poderia estar acometido. No mais famoso registro que temos da história de Dioniso, As Bacantes, de Eurípedes, o deus não faz com que a própria mãe esqueça o filho, o qual esquarteja sem reconhecer?

Existe uma objeção a essa leitura: a morte de Egeu, que, segundo este relato, vem como um castigo para Teseu em resposta às súplicas feitas por Ariadne aos numes. Entretanto, essa não é uma prova segura da não participação de Dioniso na retirada de Teseu. Invoco, para substituir a falácia dos conceitos de crime e castigo - a que nossa imersão na cultura contemporânea fatalmente nos induziria -, os conceitos de hýbris e áte, estudados de maneira bastante satisfatória por Donaldo Schüller (caso de Pândaro). 
A segunda parte do fragmento é a que diz respeito ao discurso de Ariadne. É um discurso proferido na triste manhã de Dia, quando, desperta, percebe-se sozinha na ilha, enquanto a nave de Teseu avança sobre as vagas.

É particular, também, que o discurso dirija-se a uma pessoa, em última instância:

Sicine me patriis auectam, perfide, ab aris perfide, deserto liquisti in litore, Theseus?

Pérfido, assim das aras de meu pai trazendo-me, Teseu, me deixas, pérfido, em deserta praia.

(CATULO, 1996, v.:132-133)

Como se pode perceber, o discurso de um apaixonado é sempre o de um Eu, que ama, que fala a um Tu, que é amado. Ariadne se queixa de não ter ouvidos para suas súplicas; contudo, estas são dirigidas a ninguém mais que ao próprio Teseu - deduzidas as orações dedicadas aos deuses, por se supor que, sendo entidades abstratas que regem o mundo, recebem antes clamores de justiça que um discurso organizado, não sendo essas orações mais que digressões de uma fala que as precede e teima em prosseguir -, não há outro a quem poderia dirigir-se um discurso de amor senão ao objeto desse amor:

A atopia do amor, aquilo que o faz propriamente escapar a todas as dissertações, seria que, em última instância, não é possível falar dele a não ser segundo uma estrita determinação alocutória; seja ele filosófico, gnômico, lírico ou romanesco, há sempre no discurso sobre o amor uma pessoa a quem se dirige, mesmo que essa pessoa tivesse passado ao estado de fantasma ou de criatura a vir. Ninguém tem vontade de falar de amor, se não for para alguém. (BARTHES, 1981, p. 65)

Quanto ao tema do discurso, podemos simplificá-lo em um só. Todas as acusações de perfídia, todas as de crueldade, todas as manifestações de temor se resumem a uma só afirmação, a mesma de 
todo discurso de amor, um discurso, por natureza, egoísta: “- Vês tudo o que te dou. E eu? O que me dás em troca?"

Ariadne não cobra de Teseu apenas a vida que the dera pelo fio, objeto metonímico de uma dupla relação - "dou-lhe/me a ti”. É a própria vida que pede que restitua, uma vida que uniu à sua irremediavelmente. Não há mais o auxílio paterno ou o colo materno, apenas o amado a quem se confiara, sem o qual a própria natureza parece fria e distante. O desligamento de Ariadne do mundo é quase completo; só a percepção do mundo como hostil a mantém ligada a ele (BARTHES, 1981, p. 79).

Sobretudo, é união o que busca Ariadne, qualquer que seja essa união. Como no Andrógeno de Platão, a união "é o 'prazer simples e único" (BARTHES, 1981, p. 195) do apaixonado. Ariadne deseja, fisicamente, como serva de Teseu ou, animicamente, como comungantes de igual sofrimento. Mas a lacuna que pode ser preenchida na leitura de seu discurso é a própria Ariadne. O discurso de um amor de uma personagem, que, por definição, é o mesmo discurso pelo qual a personagem se constrói.

A simetria com a personagem Dido é tão evidente que - e, talvez, porque-Ovídio (H. VII e X) e Virgílio (En. IV, 658) mostraram a heroína décadas após o poema de Catulo. E, assim como no caso virgiliano, pouco se pode extrair sobre o herói, mas muito sobre a personagem enunciadora do discurso: Ariadne é uma personagem duplamente aprisionada. O é fisicamente - a ilha é um dos lugares mais aprisionantes: circular, cercado por todos os lados, não permitindo para onde ir. E o é, psicologicamente, presa à imagem de Teseu, que, no entanto, já não se encontra. Mais uma vez é como Dido, presa ao erradio. "Me projetei no outro com tal força que, quando ele me falta, não posso me retomar, me recuperar: estou perdido para sempre". (BARTHES, 1981, p. 35)

A última, e mais curta, voz encontrada no texto em análise é a de Egeu. Nela, sem dúvida, ganha lugar de destaque o amor paternal. Outra vez, coloca-se o páthos como que uma marca discursiva. Se houve, em um primeiro momento, o sofrimento da amante abandonada, temos agora o sofrimento do pai que vê o filho partir para a sorte incerta. 
Percebamos que, se há este discurso patético do pai que sente a perda do filho, há, também, com esse mesmo discurso, o valor da uirtus ordenadora deste cosmos. Bem como no primeiro discurso que observamos, os valores heróicos de Teseu, agora, também, no de Egeu, mesmo que em menor ênfase, estão sendo destacados. Sob o triste adeus de Egeu, está sendo transmitida a feruida uirtus de Teseu, que o precipita contra o monstro, pelo bem de Atenas. Uma manifestação não só de seu valor de querer-fazer mas também de uma pietas $^{1}$ desenvolvida, já que é por sua cidade e por seu povo que decide colocar-se em risco, mesmo implicando a dor dos entes mais próximos. Em outras versões, também, foi discorrido sobre o civismo do herói, acima dos outros valores que o caracterizam, valor que o poema de Catulo torna mais vivo.

Quanto a Egeu, não se há de esquecer que ele oferece, pelo bem da cidade, aquilo que é "iucundior longa uita", reproduzindo, dessa forma, o mesmo ideal da pietas cívica de Teseu: o sacrifício pelo povo de sua cidade.

Chamo atenção para mais uma particularidade do fragmento: muito dele é demandado, como se espera, ao casal Teseu-Ariadne, mas, melhor observando, destacam-se as paixões de Ariadne e o heroísmo de Teseu. Não há recriminações ao valor de Teseu ou ao seu caráter; pelo contrário, há a tradicional figura do herói que se dirige à iniusti regis Gortínia templa (v.75) pela querida pátria e do guerreiro valoroso que enfrenta e derrota o monstro terrível. Temos um exemplo de virtus e de pietas na descrição de Teseu feita pela persona narradora.

De outra parte, temos uma Ariadne, effigies bacchantis (v. 61), perdida em furores, lançada em turbilhões pelo mísero Sancte Puer (v. 95). Ariadne está entregue à paixão e ao arrebatamento; é o mais patético dos elementos do texto, não só por seu discurso mas, também, pela imagem que o narrador dela nos faz. Ariadne, desde o momento em que Teseu chega a Creta, o vê com cúpido olhar, inflama-se até a medula e é lançada em aflições por esse sentimento, jurando dádivas

\footnotetext{
${ }^{1}$ Utilizo-me do termo, aqui, sem receio de um anacronismo de conceitos, já que tratamos de Catulo, para o qual a pietas já teria adquirido a envergadura semântica a abranger as relações do indivíduo, inclusive com o estado. vide: Rocha Pereira (1982:p. 327)
} 
aos deuses pela segurança de Teseu, já a partir do momento em que ele se dirige ao labirinto. Ariadne é o sujeito apaixonado que se desfaz perante seu Imaginário amoroso, e Catulo a coloca no momento extremo desse sentimento, o breve momento em que o objeto do amor sofre uma oscilação, o momento em que Ariadne, como o sujeito apaixonado, parece "aniquilar-se para poder ser afastado da imagem ou confundir-se com ela”. (BARTHES, 1981, p. 10)

Com essa explanação, procurei evidenciar alguns aspectos do poema. É possível compreender, por exemplo, a cena representada por ele. Dentre todas as aventuras narradas no mito de Teseu, que episódio se prestaria melhor à confrontação do individual e subjetivo - frente ao sentimento de valor cívico - que um fragmento em que estivessem em evidência não somente uma mas duas perdas de grande apelo emotivo? Os discursos de Ariadne e Egeu, que dominam quase todo o poema, sendo as únicas personagens a receber vida através de discurso próprio, ao contrário de Teseu, centro de seus discursos, que está sempre colocado em terceira pessoa no poema - aliás, é o que também se passa com os dois outros heróis do poema, Peleu e Aquiles -, são fontes dos efeitos patéticos do fragmento e, por isso, destacam-se em relação ao anúncio do texto - "heroum mira uirtutes indicate arte" -, que é realizado, mas acaba em segundo plano.

Há um confronto entre as figuras de Teseu: uma primeira, cujos atributos remetem a seu heroísmo nos discursos de Egeu e do narrador do episódio; e uma segunda, no passional discurso de Ariadne, o qual atribui a Teseu a crueldade e a perfídia como qualificativos. O conflito que se estabelece no corpo do texto entre o cívico heróico e o indivíduo passional é o conflito semelhante ao que acontece na poética do final da República: de um lado, o vigor dos jovens Poetas Novos influenciados pela cultura helenística e que elegeram o discurso amoroso como dileto assunto para suas poesias; do outro, o peso da tradição literária romana, com seus modelos de literatura grandiosa, cujos temas insistiam na utilidade da poesia como elogio do passado e ensinamento para o presente.

Na relação de oposição, estabelecida por essas duas opções, estará a chave de leitura para o poema, bem como estará a explicação 
para a escolha e o trato da versão do mito, que, entendo, é muito mais estrutural que causal.

Há coerência com a ênfase do texto e há coerência com a obra de Catulo como um todo. Inclusive a dúvida que Catulo deixa quanto a de que variante se teria utilizado. Ele não oferece detalhes que permitam definir de que corrente faria parte; antes, dá-nos a impressão de ter tomado o que havia de coincidente nas versões mais comuns e deixado em aberto aquilo em que divergiam. Problema algum, pelo contrário; o que seria um defeito em um mitógrafo, ou seja, as lacunas quanto a por que razão Teseu deixara a ilha e se Dioniso teria ou não participação ativa no que o herói fizera, em um poeta, essas polissemias são enriquecimentos ao poema.

Contudo, resta, ainda, uma última observação a ser feita. Embora, de certa forma, extrapole o corpus inicial do trabalho - que se concentraria no fragmento que se estende entre os versos 50 e 264 -, tem certa coerência pensar o contexto sintagmático desse fragmento: ainda falta observarmos de que maneira este mito se liga aos outros dois mitos que estão inseridos no poema, o de Peleu e o de Aquiles.

Quanto a Peleu, pouco do poema é dedicado a ele, embora tenha em suas bodas o motivo central, menos de 50 versos. Peleu é tido como o mais ditoso dos heróis louvados pela persona narradora da história e, por uma questão simples, qual seja: foi-lhe dada uma esposa deusa. A viagem de Argos não passa de uma breve introdução, que, sequer, marca os feitos do herói, chamado de Coluna da Tessália - qualificativo que é a única marca épica que Peleu vai receber. Mesmo o que se diz após a viagem dos argonautas, i.e., o elogio ao divo casamento de Peleu, mostra, antes, um rei próspero que um herói ativo. Como se o "finito tempore" do verso 31 fosse o tempo, exatamente, dos feitos heróicos de Peleu.

A história de Aquiles toma quase toda a parte final do poema. É contada por uma nova voz que se constrói no poema, a das Parcas. Assim como o manto que contava a história de Teseu e Ariadne, o canto das Parcas inicia uma nova digressão, se bem que com ligações mais fortes com as bodas por marcas que dão o discurso como direcionado a Peleu.

O canto das Parcas revelará o futuro do rebento do casal, que glorificará o nome do pai por sua força. Sublinha-se, contudo, que, ao 
contrário do que observamos com Teseu, não há marcas de piedade filial ou mesmo pela cidade ou pelo seu povo. Com efeito, aos feitos de Aquiles não são atribuídas quaisquer motivações. Aliás, as proezas do herói na narrativa feita pelas Parcas merecem uma atenção cuidadosa.

O fato é que as cenas evocadas pelas deusas não dão, em momento algum, ideia de feitos gloriosos; na verdade, há imagens duras e cruéis, que remetem antes a atos dignos de lamentação que de louvor: seus feitos serão cantados pelas mães em funerais de filhos (v. 349-352), sangue manará dos campos (v. 344), montanhas de mortos às margens do Escamandro (v. 357-360). À imagem do ceifador, Aquiles é, antes de tudo, um tirador de vidas, exatamente o oposto do que se celebra, a união que gerará nova vida. Mesmo em suas bodas, e após sua morte, o Pelida continuará "ceifando" vidas, a de sua pretendida, Polixena.

Parece claro que há uma oposição entre a feliz união de Peleu e Tétis - uma vez que Catulo retira do poema todos os complicadores que outras versões trazem - e a história de Aquiles, que parece vir ao mundo para causar a dor.

Antes que seja levantada a questão de uma leitura anacrônica que a contemporaneidade tende a fazer do comandante dos mirmídones, faço uma ressalva. É indiscutível que Aquiles é o modelo de areté guerreira, grande modelo da Antiguidade por sua fúria e sua força. Contudo, parece que, como acontece na atualidade, os homens do fim da República e do início do Império rejeitavam essa virtude ofensiva do herói. Por isso começa a haver, sobretudo por parte dos poetas, uma rejeição à guerra. A IV Bucólica coincide o retorno ao período de ouro com o início da paz. São famosas as rejeições de Horácio e Ovídio pelas guerras. Horácio $(O . \mathrm{IV}, 9)$ reserva um elogio, apenas, dentre os heróis homéricos, a Heitor.

Nesse ponto ficam evidentes duas coisas, a saber: a gradação existente de Peleu, Teseu e Aquiles, em ordem crescente, do menos épico para o mais épico, inversamente, do mais eufórico para o mais disfórico. Essa constatação nos coloca em quase perfeita concordância com as palavras de Galán, quando esta afirma o seguinte: "La problemática no es el heroísmo en si, sino la compleja situacíon que origina su relacíon con lo pasional." (GALÁN, 2003, p. 38). Façamos uma breve leitura, porém pouco mais analítica. 
A melhor comunhão entre épico e passional encontra-se em Peleu e Tétis. As suas bodas são expressão de uma sublime felicidade, em que divino e humano compartilham das mesmas comemorações. Contudo, como já observamos, o lado épico de Peleu encontra-se adormecido, apagado durante a narrativa, suprimido pelo seu lado passional, incensus amore!

Aquiles, por outro lado, é o mais épico de todos. O filho de Peleu encontra-se à vontade somente no campo de batalha, e é somente na guerra que encontra seu lugar, como um de seus símbolos e estandartes. Tudo que é dito sobre o herói neste poema remete às guerras e à morte. A união amorosa de Aquiles destacada no poema é com Políxena, a qual o desejo do guerreiro, como último feito, tombou decapitada.

Por último encontramos o meio termo entre o Eácida e seu filho. O poema reserva versos para descrição de um feito recém-acabado por Teseu: a morte do Minotauro. Destaque-se que essa morte não é colocada como finalidade em si - o canto das Parcas induz o leitor a ver que Aquiles vive apenas para a guerra e para a matança; ela é parte de um ato que visa ao restabelecimento de uma dike rompida por um tributo cruel de um iniustis regis. A aventura de Teseu parece receber sanção do poeta como ato digno, de coragem e desprendimento. A paixão neste episódio é encarnada por Ariadne e, sobre isso, já houve apontamentos, mas recapitulemos.

A oposição entre Teseu e Ariadne é diametral. De um lado, temos Teseu, modelo de virtude cívica - como foi dito anteriormente -, herói dotado de grande piedade, em suas três vias: deuses, pátria e antepassados. Teseu não receia sacrificar-se pelo bem de sua Atenas e pela honra do nome de seu pai. De outro, Ariadne, na via oposta, abandona os braços da mãe, sua casa e o dever filial pela felicidade amorosa, i.e., individual.

Teseu e Ariadne não habitam o mesmo mundo (como lembrou o prof. ${ }^{\circ}$ Ahl, o fim do poema prenuncia o destino celeste de Ariadne, enquanto Teseu será aprisionado no Hades). Ariadne lança ao vento os valores de Teseu, contraditoriamente, quando o ajuda a vencer as provas de Creta. 
A disjunção presente entre Teseu e Ariadne é recorrente na mitologia: Medeia traiu a Cólquida e seu pai Eeetes por Jasão, pela paixão descontrolada pelo herói argólida. De nada lhe valeu tudo isso para ter Jasão, que a deixa, e faz da feiticeira uma peregrina sem lar e mal vista por onde passava. A filha de Niso, cuja madeixa roxa tornava-o invencível, traiu também seu reino e seu pai por amor a Minos. Ovídio põe nos lábios de Minos o seguinte agradecimento por este ímpio ato de amor:

\begin{abstract}
Ó infâmia do nosso tempo" que os deuses te escorrassem do nosso mundo! Que a terra e o mar te sejam negados! Decerto, não tolerarei que tamanho monstro ponha os pés em Creta, o berço de Júpiter, que é o meu mundo.
\end{abstract}

(Met.VIII, 97-99)

A escolha de Catulo parece também evidente, neste impasse. Concorde com tudo o que sua poética defendia e que demonstramos no capítulo anterior, há, tanto no plano formal como no plano temático, uma rejeição do grandioso e uma valorização daquilo que era chamado de obra menor por sua época - e na defesa da qual Horácio ainda escreverá muitos versos. Se o mito apresenta uma questão, um conflito, o poeta o soluciona seguindo as prerrogativas neotéricas. O caminho épico é um caminho de muitas perdas, de sofrimentos, de morte. Teseu paga com a vida de Egeu pelos seus feitos. Mas Catulo, ao menos, reserva a felicidade final àqueles que se entregam ao amor em detrimento da épica. Por sua vez, Peleu é o mais venturoso dos heróis; Ariadne encontra o amor de Dioniso.

Não podemos deixar de observar, já aqui, uma transgressão da qual Virgílio, Horácio e Ovídio far-se-ão partidários e defensores: o reclamar para poesia uma independência frente aos valores morais ou estatais. Não é de se estranhar que o status quo invoque, de maneira surpreendentemente desmedida, a tabula VIII para punir carmina - o que Plínio (Nat. H. XXVIII, V,17) já contesta - ou traz à tona a lex Cornelia de iniuriis e a lex Cornelia maiestatis, ambas com significativo potencial de controle de ideias, outrora usadas com outros fins, como aponta Tácito: 
Esta lei [lesae maiestatis] tinha para os antigos o mesmo nome, mas os atos chamados a juízo eram outros; punia os que atraiçoavam o exército, os que agitavam com sedição a plebe, e os que por criminosa administração ofendiam a majestade do povo romano: castigava as ações, mas as palavras eram impunes. Augusto, como primeiro, aplicou esta lei ao conhecimento de uns libelos escandalosos de Cássio Severo, em que infamava homens e mulheres ilustres. (An. I, 72. Trad. Leopoldo Pereira).

O autor, seu estilo e suas virtudes são moedas na nova economia de avaliação dos textos, e não é coincidência que a atividade censora se intensifique neste momento. A lex Cornelia foi uma reação natural das instituições controladoras do estado e da circulação de ideias a uma instância que se autonomizava perigosamente. Todos deveriam temer a "coroa de câncer", ${ }^{2}$ como lembra Propércio. O texto de Filodemo de Gadara, tornado público há pouco, graças ao trabalho da equipe liderada pelo prof. ${ }^{\circ}$ Richard Janko, é muito importante para que percebamos o tamanho do esforço que o século de Cícero e Augusto fazia para compreender a literatura por leis próprias, diversas da moral, da filosofia ou, ainda, da gramática.

Ora, quando Múmio recebe a vultosa oferta de 600.000 sestércios por uma pintura de Baco feita por Aristides, ele manda-a para Roma a fim de descobrir a virtude [virtutis] que ela possuía (Nat. H. XXXV, 8, 24). Se Verres aparece como o mais antigo colecionador que podemos averiguar em Roma (Verr. II, 4), logo outras coleções vão tornando-se comuns, como nos atesta Ovídio (Tr. II, 521-4) falando sobre o imperador e Petrônio (LXXXIII), dando uma pinacotheca como palco de encontro para Encólpio e Eumolpo. Mesmo a mais antiga cópia de uma estátua do período clássico grego, o Diadoumenos, data de fins do século II a.C. e foi encontrada em uma rica casa de Delos, mesma época do naufrágio de dois navios nas costas de Antícera.

${ }^{2} \mathrm{O}$ áureo de Augusto, cunhado provavelmente em 19 a.C., tinha o caranguejo em seu verso. 
Ela indica o nascimento de uma atividade produtiva, organizada e sistemática, apta a satisfazer uma demanda de bens artísticos de parte da abastada burguesia tardohelenística. Ao ingressar na esfera do privado, altera-se o significado da escultura: não mais obra de arte de per se, mas elemento decorativo subordinado ao mobiliário e à arquitetura residencial. De seu emprego estão ausentes motivações ideológicas ou políticas, restando apenas a intenção de evocar célebres obras primas do passado, de tornar manifesta a pertinência do proprietário a um definido horizonte cultural. (GASPARRI, 2008, p. 30)

O que vemos na poesia de Catulo se assemelha ao que Gasparri aponta nas artes plásticas, no entanto, há algo mais que o crítico italiano não destaca. Privada do que Gasparri chama de sentido ideológico, i.e., sua ação no mundo empírico, a arte precisa afirmar-se por si mesma. A disforia das virtudes cívicas que aparece em Catulo é essa afirmação da arte, que começa a se autonomizar e que, neste momento, é razão de um outro terror, distinto do terror expresso por Platão - que teme que os cidadãos interpretem peças (Leis VII, 817c-d) ou deseja expulsar os artistas da cidade (Rep. X, 594a-b) -, um terror que se manifesta à medida da constatação da existência de um novo mundo, que só existe na esfera da arte.

\section{Referências}

BARTHES, R. Fragmentos de um discurso amoroso. 2. ed. Trad. Hortênsia dos Santos. Rio de Janeiro: Francisco Alves, 1981.

CATULO. O livro de Catulo. Tradução comentada dos poemas de Catulo de João Ângelo de Oliva Neto. São Paulo: Edusp, 1996.

CÍCERO. Obras completas de Marco Tulio Cicerón. Buenos Aires: Grandes Librerías Anaconda, 1946. $6 \mathrm{v}$.

GALÁN, L. El Carmen 64 de Catulo. La Plata: Igitur, 2003.

GASPARRI, C. O Clássico copiado. In: MARQUES, L. (Org.). A fábrica do antigo. São Paulo: Ed. Unicamp, 2008. 
HORÁCIO. Odes e epodos. Trad. Bento Prado de Almeida Ferraz. São Paulo: Martins Fontes, 2003.

KENNEY E. J.; CLAUSEN W. V. Historia de la Literatura Clásica - II. Tradução de Elena Bombín. Madrid: Gredos, 1989.

MENDES, M. O. Virgílio Brazileiro ou tradução do poeta latino. Paris: Typographia W. Remquet, 1858.

OVÍDIO. Metamorfoses. Trad. Paulo F. Alberto. Lisboa: Cotovia, 2007. OVÍDIO. Heroides. Trad. Walter Vergana. Rio de Janeiro: Museu das Armas Ferreira Cunha, 1975.

OVÍDIO. Tristia. Ed. Arthur Leslie Wheeler. Cambridge: MA-Harvard University Press, 1939.

PLATÃO. A República. Tradução de J. Guinsburg. São Paulo: Perspectiva, 2014.

PLINIO. Historia Natural. Tradução de Josefa Cantó et al. 2. ed. Madrid: Ediciones Catedra, 2007.

ROCHA PEREIRA, M. H. da. Estudos de História da Cultura Clássica. Lisboa: Fundação Calouste Gulbenkian, 1982. II v.

Recebido em 30 de julho de 2017. Aprovado em 30 de setembro de 2017. 